\title{
Stage IV Adrenal Cortex Carcinoma AJCC v7
}

National Cancer Institute

\section{Source}

National Cancer Institute. Stage IV Adrenal Cortex Carcinoma A/CC v7. NCI Thesaurus.

Code C9217.

Stage IV includes: (T3, N1, M0); (T4, N0, M0); (T4, N1, M0); (Any T, Any N, M1). T3:

Tumor of any size with local invasion, but not invading adjacent organs. T4: Tumor of any size with invasion of adjacent organs. N1: Metastasis in regional lymph node(s). N0: No regional lymph node metastasis. M0: No distant metastasis. M1: Distant metastasis. (AJCC 7th ed.) 